\title{
Effect of Mg Addition on the Structure and Properties of Al-4.5 Cu-3.4 Fe In-Situ Cast Composite
}

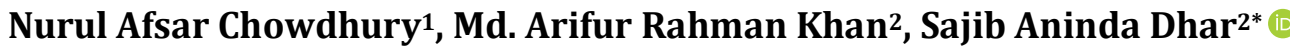 \\ ${ }^{1}$ Department of Materials and Metallurgical Engineering, Bangladesh University of Engineering and Technology, Dhaka, \\ Bangladesh \\ ${ }^{2}$ Pilot Plant and Process Development Centre (PP \& PDC), Bangladesh Council of Scientific and Industrial Research, Dhaka, \\ Bangladesh \\ Email: *sajibaninda89@gmail.com
}

How to cite this paper: Chowdhury, N.A., Khan, M.A.R. and Dhar, S.A. (2020) Effect of $\mathrm{Mg}$ Addition on the Structure and Properties of Al-4.5 Cu-3.4 Fe In-Situ Cast Composite. Journal of Materials Science and Chemical Engineering, 8, 66-73.

https://doi.org/10.4236/msce.2020.83005

Received: January 14, 2020

Accepted: March 10, 2020

Published: March 13, 2020

Copyright $\odot 2020$ by author(s) and Scientific Research Publishing Inc. This work is licensed under the Creative Commons Attribution International License (CC BY 4.0).

http://creativecommons.org/licenses/by/4.0/

\begin{abstract}
Ternary Al-4.5 (wt\%) Cu-3.4 (wt\%) Fe in-situ composite was prepared at $1100^{\circ} \mathrm{C}$ by conventional casting method. However, this particular alloy contains larger needle-shaped intermetallics of $\mathrm{Al}_{3} \mathrm{Fe}$ phase. These exert adverse effect on the mechanical properties of the alloys. The larger shape and uneven orientation of the intermetallic were found to be responsible for the degradation of properties. The main purpose of this study was to modify the geometry of those needles by adding magnesium $(\mathrm{Mg})$ as a fourth material. A series of alloys were prepared by adding 4, 6, 8, 10, wt\% Mg in Al-4.5 (wt\%) Cu-3.4 (wt\%) Fe alloy. Microstructures were observed by optical microscopy. Mechanical properties like ultimate tensile strength, $\%$ elongation, $\%$ area reduction, hardness and wear test were determined. The study revealed that $\mathrm{Mg}$ transformed the needles of $\mathrm{Al}_{3} \mathrm{Fe}$ into globular shape which gave the alloys better mechanical properties.
\end{abstract}

\section{Keywords}

Metal Matrix Composites (MMCs), Intermetallic Compounds, $\mathrm{Al}-\mathrm{Cu}-\mathrm{Fe}$ Alloy, In-Situ Composite, Mg Addition

\section{Introduction}

Materials with high stiffness and low specific gravity are required in the arena of aerospace, weapon, automobiles, electronics and sports industry [1]. For that reason, metal matrix composites (MMCs) came into play in commercial produc- 
tion in early 1990s [2]. Light matrix is combined with relatively harder reinforcing particles in reason metal matrix composites (MMCs). For many of these applications MMCs are more reliable than conventional alloys. MMCs provide suitable properties like high elastic modulus, strength, hardness and wear resistance [3]. Moreover, they offer cheaper and easier techniques for fabrication. These properties are not developed from continuous fibres reinforcement rather come from the randomly distributed particles. This phenomenon can be achieved either from in situ composite processing or powder metallurgy process [4]. In situ technique allows reinforcing particles to precipitate from within the alloy during the solidification. This technique offers certain benefits like uniformity of particles, ease of processing and low cost production [5]. As a consequence, aluminium has been adopted for many years as a substitute of steel or cast iron due to the demand for lighter-weight materials in material processing. Pure $\mathrm{Al}$ is soft and not recommended for load bearing and high temperature applications although $\mathrm{Al}$ alloy shows required efficiency under those circumstances [6]. Since different alloying elements exert different properties in $\mathrm{Al}$ alloy, metallurgists all over the world are creating different $\mathrm{Al}$ alloys for understanding the suitability of alloying element addition in Al. It is also necessary to determine the optimum quantity of alloying element addition that has to be made for acquiring the desired properties under applied conditions. But there were difficulties in producing good quality composites due to adverse chemical reactions between these fibers and the matrix [7]. With successive developments in the structures of different fibres and intermetallics, this field of alloy modification has become a prime interest for scientists. Emerging sectors of Military and Aerospace Industries greatly require materials with high strength-to-weight ratios or high modulus-to-weight ratios. Materials with these properties can also withstand severe high temperature as well as corrosive environments [8]. Although it makes their production complicated and enhanced costing. In order to ensure cost-effective manufacturing techniques, reinforcement of in-situ particles in composites is a popular way for sustainable commercial applications [9]. To reduce their cost for increasing easy usage cost-effective manufacturing techniques such as in-situ particle reinforced composites will find commercial applications. The uprising demand for excellent mechanical and wear resistance properties and high temperature applications have provided the incentive for concentrated research in light composite materials. Hence to develop the properties of both Iron $(\mathrm{Fe})$ and Aluminium ( $\mathrm{Al})$ at a time, these elements were targeted for creating alloys. Under equilibrium condition, Al-Fe binary system exhibits the presence of intermetallic phase of $\mathrm{Al}_{3} \mathrm{Fe}$ [10]. It can act as in situ reinforcing particle [11]. A popular method for the production of in situ composites is casting technique [12]. On the other hand, $\mathrm{Cu}$ can be added to this system to achieve age hardenable matrix which in turn improves the mechanical properties of the material [13]. The shape of intermetallics is a critical factor as it can be detrimental to the mechanical properties of the alloys. 
Therefore, the aim of this research is to modify the shape of these intermetallics and to possess optimum mechanical properties. This work focused on alloying Al-4.5 Cu-3.4 Fe system with a fourth element. Magnesiem (Mg) of different concentrations (4 - 10, wt\%) were alloyed with Al-4.5 Cu-3.4 Fe system with the aim of modifying size of intermetalics and getting better mechanical properties.

\section{Experimental Procedure}

\subsection{Materials}

Commercially available pure aluminium ingots ( $99.7 \%$ purity, Balco, India), copper ingots (99.85\% pure, Rajshi, India) and pure iron ingot (99.9\% Pure, Taigang, China) were used to cast Al-4.5 Cu-3.4 Fe master alloy. Addition of $\mathrm{Mg}$ to the Al-4.5 $\mathrm{Cu}-3.4 \mathrm{Fe}$ master alloy was done by pure magnesium rod (99.9\% pure, MS Metalshipper, USA).

\subsection{Method}

A graphite crucible was used to cast the products. Small metallic pieces from aluminium ingot were cut and melted in graphite crucible at $800^{\circ} \mathrm{C}$. After that, small pieces of copper were added to the melt. This step was followed by required amount of pure iron addition as metallic chips. Temperature was raised to $1100^{\circ} \mathrm{C}$ and the melt was stirred for 20 minutes for complete dissolution and homogenization. A cast iron mould was used to cast the melt. The mould was preheated to $500^{\circ} \mathrm{C}$ to avoid surface shrinkage. Then the Al-4.5 Cu-3.4 Fe melt was poured into the prepared mould and allowed to solidify slowly. The solid ingot of desired composition was then removed from the mould and used as master alloy for subsequent alloying. Al-4.5 Cu-3.4 Fe master alloy of definite weight was taken into a graphite crucible and the temperature was raised to $900^{\circ} \mathrm{C}$. After adding suitable amount of fluxing materials, desired amount of $\mathrm{Mg}$ was added to the melt and stirred carefully. Then the crucible was kept in the furnace at $900^{\circ} \mathrm{C}$ for about 30 minutes for homogenization. The melt was then poured into the preheated cast iron mould. Following the above mentioned process $4 \%, 6 \%, 8 \%, 10 \% \mathrm{Mg}$ was added to the master alloy and four different alloy compositions were prepared.

Optical microscopy was performed to observe surface morphologies. An optical microscope (Olympus PMG3) was used to examine the microstructures. Samples of $2 \mathrm{~cm} \times 2 \mathrm{~cm}$ were sectioned from parent alloy, mount and grinded in $\mathrm{SiC}$ abrasives. After wet polishing in $1 \mu \mathrm{m} \mathrm{Al}_{2} \mathrm{O}_{3}$ abrasives, they were etched chemically by Krolls Reagent (Distilled Water-92 ml, Nitric Acid-6 ml, Hydrofluoric Acid-2 ml). Tensile properties were determined using Instron 3369 (USA) universal testing machine. The test speed was $2 \mathrm{~mm} / \mathrm{min}$. Hardness was measured by a hardness tester (Future-Tech Corp., model FR-1E, Japan) in HRF scale. 5 repetition was performed for each sample to measure tensile properties and hardness. Wear study was done by pin on disc method. Three different rotation periods $(5,10,15$ minutes) were maintained at constant rotation speed. 


\section{Results and Discussion}

\subsection{Optical Microscopy}

Microstructures of the samples were observed by optical microscopy. The optical micrographs of as-cast Al-4.5 $\mathrm{Cu}-3.4 \mathrm{Fe}$ composite and $4 \%-10 \% \mathrm{Mg}$ added Al-4.5 Cu-3.4 Fe composites are illustrated in Figure 1.

As in Figure 1(a), large needle like structures are evident in as cast Al-4.5 $\mathrm{Cu}-3.4 \mathrm{Fe}$ composites. This secondary phase can be identified as $\mathrm{Al}_{3} \mathrm{Fe}$ phase [13]. The reinforcing particles were apparently bigger in size and unevenly distributed in the matrix. With addition of $4 \%$ (Figure 1(b)) and 6\% Mg (Figure $1(c)$ ), the larger needle shaped secondary phases got finer in size. Particularly, the spheroidization of $\mathrm{Al}_{3} \mathrm{Fe}$ needles started with the addition of $6 \% \mathrm{Mg}$. The

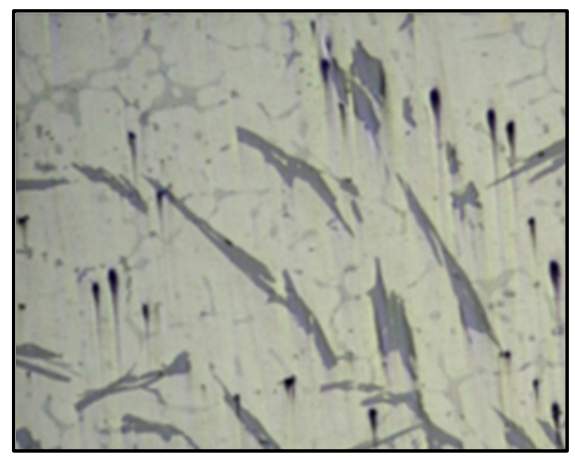

(a)

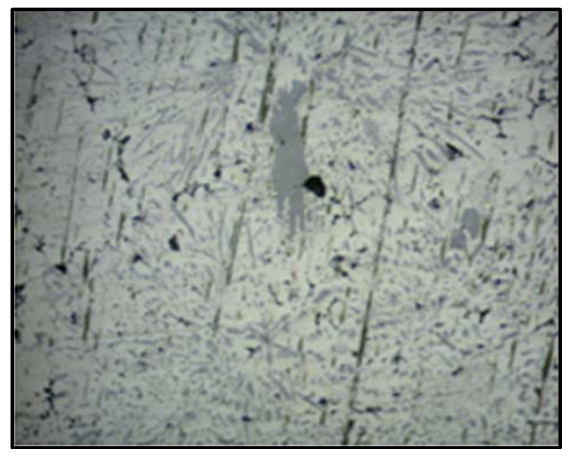

(c)

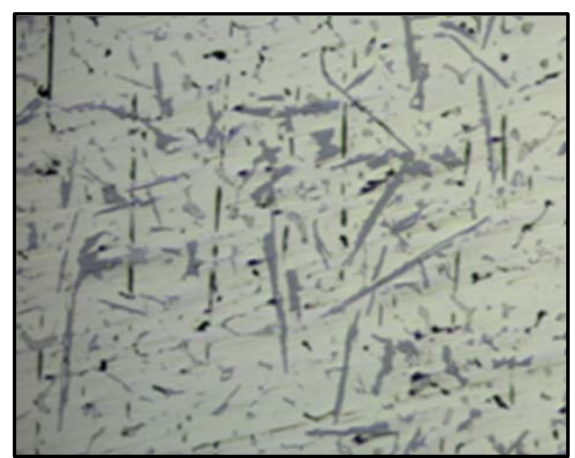

(b)

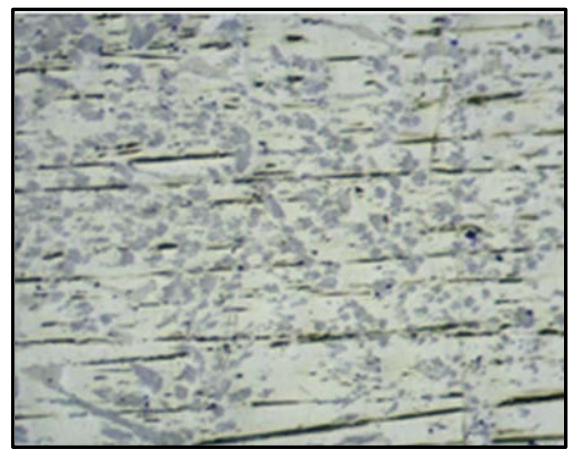

(d)

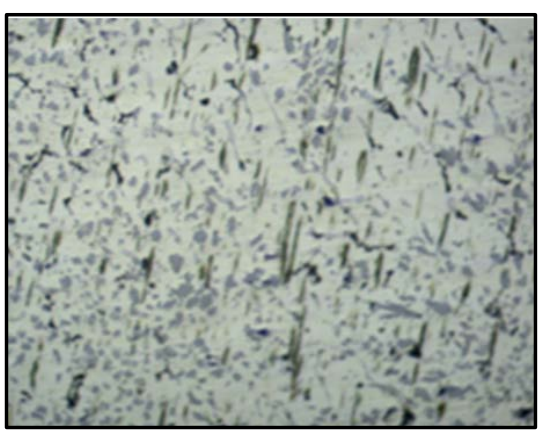

(e)

Figure 1. Optical microscopy of Al-4.5 Cu-3.4 Fe alloys with (a) as-cast condition; (b) $4 \%$ $\mathrm{Mg}$ addition; (c) 6\% Mg addition; (d) $8 \% \mathrm{Mg}$ addition; (e) $10 \% \mathrm{Mg}$ addition. 
shape change played a crucial role in the modification of mechanical properties. Precipitation strengthening was predominant in this stage of transformation. The increment of tensile properties was the result of this transformation. Upon further addition of $\mathrm{Mg}$ (Figure 1(d) and Figure 1(e)) the spheroidization process advanced and formed spherical shape particles.

\subsection{Tensile Properties}

Figure 2 presents the tensile properties ((a) ultimate tensile strength, (b) \%, elongation, (c) \%, area reduction) of different alloys of Al-4.5 Cu-3.4 Fe system as a function of $\%, \mathrm{Mg}$ addition. From Figure 2(a), it is shown that ultimate tensile strength of the alloys increased as $\%, \mathrm{Mg}$ addition was raised. This increment may be attributed to the precipitation strengthening that came from transformation of needle shaped phases to the spherical particles.

However, the ultimate tensile strength downgraded contrastingly for $10 \% \mathrm{Mg}$ addition. There is a tendency of $\mathrm{Al}_{3} \mathrm{Fe}$ intermetallics to gather in the grain boundary region when $\mathrm{Mg}$ is added more than $10 \%$. This was the reason of that decrement. The \%, elongation decreased as $\mathrm{Mg}$ addition increased up to $8 \%$ (Figure 2(b)). It was due to the formation of globules in the matrix that was harder than the needles [14]. For, 10\% Mg added Al-4.5 Cu-3.4 Fe alloy the \%, elongation increased insignificantly. The \%, area reduction for the alloys followed an inconsistent trend (Figure 2(c)). It increased up to $6 \% \mathrm{Mg}$ addition followed by a sharp decline. At 6\% Mg added $\mathrm{Al}-4.5 \mathrm{Cu}-3.4 \mathrm{Fe}$ alloy spheroidization started.

\subsection{Wear Property}

Figure 3 illustrates variation in wear loss at three different rotation periods ( 5 , 10,15 minutes) as a function of \%, $\mathrm{Mg}$ addition in $\mathrm{Al}-4.5 \mathrm{Cu}-3.4 \mathrm{Fe}$ alloys. The

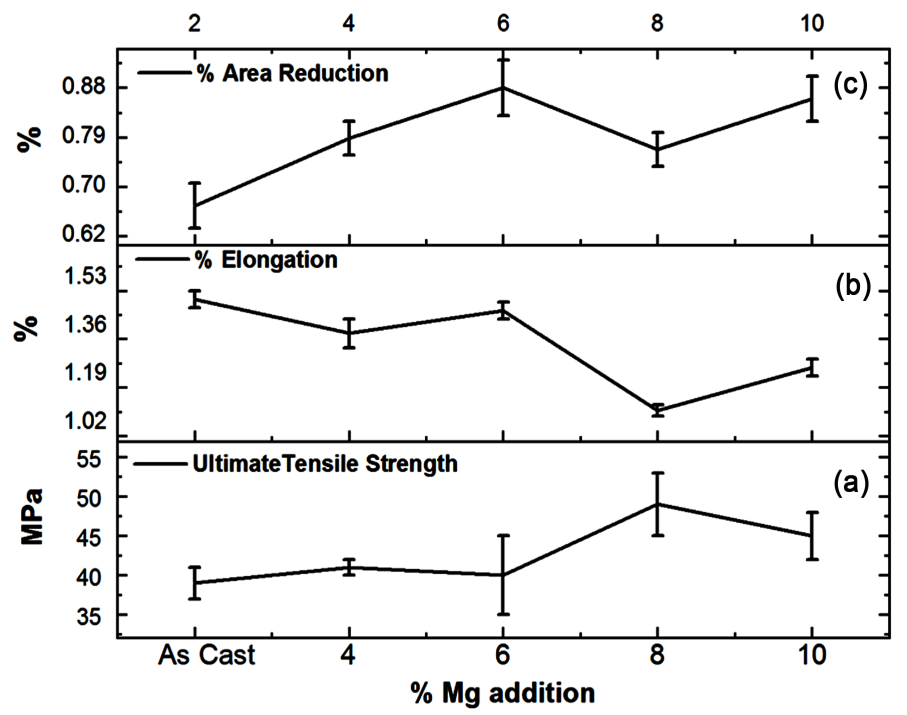

Figure 2. Tensile Properties of (\%) Mg added Al-4.5 Cu-3.4 Fe alloys ((a) ultimate tensile strength; (b) \% elongation; (c) \% reduction). 


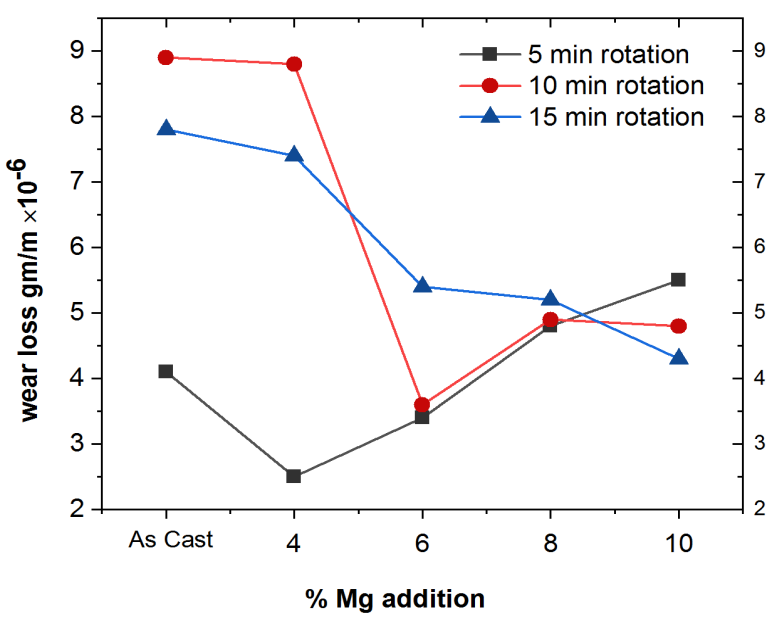

Figure 3. Wear Property of different concentration of \%, Mg added Al-4.5 Cu-3.4 Fe alloys at three different rotation periods $(5,10,15 \mathrm{~min})$.

wear rate generally increases with the rotation period for every alloy system. This wear rate was effectively modified by $\mathrm{Mg}$ addition. Wear rate decreased with $\mathrm{Mg}$ addition for all rotation periods with some exceptions. In case of the highest rotation period of 15 minutes, wear rate decreased gradually from $7.8 \times$ $10^{-6} \mathrm{gm} / \mathrm{m}$ to $4.3 \times 10^{-6} \mathrm{gm} / \mathrm{m}$ which confirmed good performance of $\mathrm{Mg}$ added composites for longer period. The reduction of wear loss rate was an anticipated phenomenon because the lengths of needle shaped $\mathrm{Al}_{3} \mathrm{Fe}$ secondary phases became shorter with $\mathrm{Mg}$ addition. Moreover, $\mathrm{Mg}$ addition transformed the needles into globular precipitates. Those globular precipitates are harder than the needles [14]. These harder phases upgraded the wear resistance of the alloys [15]. For 5 minute rotation period, the wear loss decreased up to $4 \% \mathrm{Mg}$ addition and then contrastingly got aggravated. This exceptional phenomenon may be attributed to the presence of deleterious $\mathrm{CuAl}_{2}$ Phases in the matrix [16]. Apart from this, addition of $4 \% \mathrm{Mg}$ did not improve wear resistance significantly but higher percentage of $\mathrm{Mg}$ addition revealed better wear performances.

\subsection{Hardness}

Figure 4 represents hardness of different alloys of Al-4.5 Cu-3.4 Fe system as a function of \%, Mg addition. Hardness had been calculated in HRF scale. It is evident from Figure 4 that $\mathrm{Mg}$ addition resulted in better hardness than as-cast Al-4.5 Cu-3.4 Fe alloy. Al-4.5 $\mathrm{Cu}-3.4 \mathrm{Fe}$ as-cast composite showed hardness value of $71.7 \mathrm{HRF}$. With addition of $\mathrm{Mg}$, hardness values of the alloys increased gradually up to $8 \% \mathrm{Mg}$ addition. The alloy with $8 \% \mathrm{Mg}$ addition exhibited the highest hardness value. The transformation of needle shaped $\mathrm{Al}_{3} \mathrm{Fe}$ secondary phases into spherical shape was the main reason behind increase of hardness as those spherical shapes are hard in nature. For $10 \% \mathrm{Mg}$ added $\mathrm{Al}-4.5 \mathrm{Cu}-3.4 \mathrm{Fe}$ alloy, the hardness value reduced slightly. The $\mathrm{Al}_{3} \mathrm{Fe}$ intermetallic compounds tend to gather at the grain boundaries, which could be a reason for low hardness of $10 \% \mathrm{Mg}$ added alloy. 


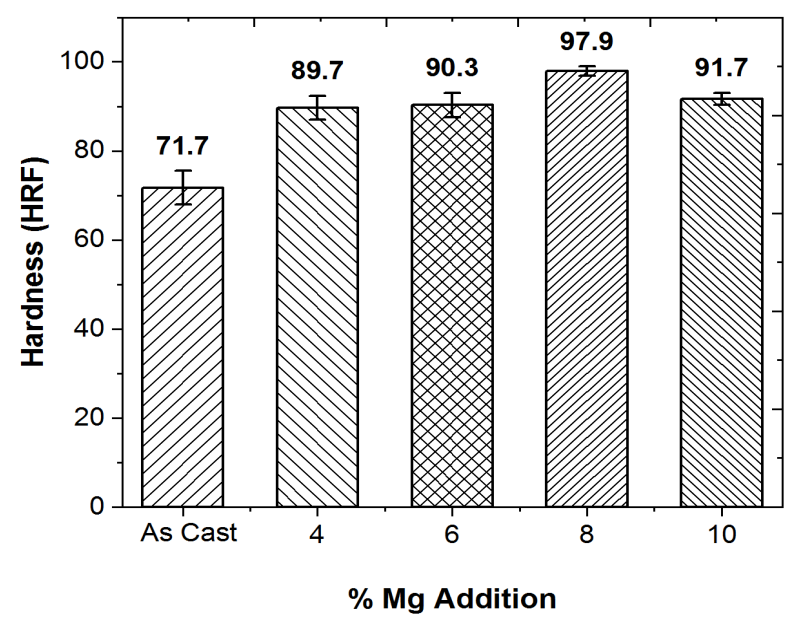

Figure 4. Hardness of different concentration of \%, Mg added Al-4.5 Cu-3.4 Fe (HRF scale).

\section{Conclusion}

In this research, the shape of the needle like $\mathrm{Al}_{3} \mathrm{Fe}$ intermetallic particles in the Al-4.5 (wt\%) Cu-3.4 (wt\%) Fe cast in-situ composite was modified by suitable $\mathrm{Mg}$ addition. The structure and the properties were investigated by optical microscopy, tensile, wear properties and hardness measurements. Based on the results obtained, it can be inferred that it is possible to modify the needle like $\mathrm{Al}_{3} \mathrm{Fe}$ intermetallic particles in the $\mathrm{Al}-4.5 \% \mathrm{Cu}-3.4 \%$ Fe cast in-situ composite by $\mathrm{Mg}$ addition. With $\mathrm{Mg}$ addition higher than $8 \%$, the particles became spherical and evenly distributed in the matrix. Ultimate tensile strength, wear resistance and hardness were increased by Mg addition than as cast Al-4.5 (wt\%) Cu-3.4 (wt\%) $\mathrm{Fe}$. In future work, the rolling effect can be observed on $\mathrm{Mg}$ added $\mathrm{Al}-4.5$ (wt\%) Cu-3.4 (wt\%) Fe composite.

\section{Acknowledgements}

This research work was supported by Department of Materials and Metallurgical Engineering, Bangladesh University of Engineering and Technology and Pilot Plant and Process Development Centre (PP \& PDC), Bangladesh Council of Scientific and Industrial Research.

\section{Conflicts of Interest}

The authors declare no conflicts of interest regarding the publication of this paper.

\section{References}

[1] Laplanche, G., et al. (2010) Microstructural and Mechanical Study of an Al Matrix Composite Reinforced by Al-Cu-Fe Icosahedral Particles. Journal of Materials Research, 25, 957-965. https://doi.org/10.1557/JMR.2010.0118

[2] Prasad, S. and Asthana, R. (2004) Aluminum Metal-Matrix Composites for Automotive Applications: Tribological Considerations. Tribology Letters, 17, 445-453. 
https://doi.org/10.1023/B:TRIL.0000044492.91991.f3

[3] Lloyd, D. (1994) Particle Reinforced Aluminium and Magnesium Matrix Composites. International Materials Reviews, 39, 1-23.

https://doi.org/10.1179/imr.1994.39.1.1

[4] Aikin, R. (1997) The Mechanical Properties of in-Situ Composites. Journal of Operations Management, 49, Article No. 35. https://doi.org/10.1007/BF02914400

[5] Fishman, S. (1994) In Situ Composites. Science and Technology. TMS, Warrendale, PA.

[6] Gupta, M. and Ling, S. (1999) Microstructure and Mechanical Properties of Hypo/Hyper-Eutectic Al-Si Alloys Synthesized Using a Near-Net Shape Forming Technique. Journal of Alloys and Compounds, 287, 284-294. https://doi.org/10.1016/S0925-8388(99)00062-6

[7] Gowri, S. and Samuel, F. (1994) Effect of Alloying Elements on the Solidification Characteristics and Microstructure of Al-Si-Cu-Mg-Fe 380 Alloy. Metallurgical and Materials Transactions A, 25, 437-448. https://doi.org/10.1007/BF02647989

[8] Miyamoto, Y., et al. (2013) Functionally Graded Materials: Design, Processing and Applications. Volume 5, Springer Science \& Business Media, New York.

[9] Sjölander, E. and Seifeddine, S. (2010) The Heat Treatment of Al-Si-Cu-Mg Casting Alloys. Journal of Materials Processing Technology, 210, 1249-1259.

https://doi.org/10.1016/j.jmatprotec.2010.03.020

[10] Lendvai, J. (1987) The Structure of DC Cast Al-Fe and Al-Fe-Si Alloys. In: Materials Science Forum, Trans Tech Publications Ltd., Switzerland. https://doi.org/10.4028/www.scientific.net/MSF.13-14.101

[11] Griger, A., et al. (1987) On the Phase Diagrams of the Al-Fe and Al-Fe-Si Systems. In: Materials Science Forum, Trans Tech Publications Ltd., Switzerland. https://doi.org/10.4028/www.scientific.net/MSF.13-14.331

[12] Kabir, M.S., et al. (2014) Effect of Mg on the Microstructure and Indentation Hardness of as-Cast Al-4.5 Cu-3.4 Fe in-Situ Composite. 2014 9th International Forum on Strategic Technology (IFOST), Bangladesh, 21-23 October 2014, 432-435. https://doi.org/10.1109/IFOST.2014.6991156

[13] Hossain, M.D., Kabir, M.S. and Kurny, A. (2015) Effect of Mg on the Corrosion Behaviour of As-Cast and Heat Treated Al-4.5 Cu-3.4 Fe in-Situ Composites. Journal of the Institution of Engineers (India): Series D, 96, 113-122. https://doi.org/10.1007/s40033-015-0066-8

[14] Ahmed, S., Haseeb, A. and Kurny, A. (2007) Study of the Wear Behaviour of Al-4.5\% $\mathrm{Cu}-3.4 \%$ Fe in Situ Composite: Effect of Thermal and Mechanical Processing. Journal of Materials Processing Technology, 182, 327-332. https://doi.org/10.1016/j.jmatprotec.2006.08.009

[15] Miyoshi, K. (1989) Design, Development, and Applications of Novel Techniques for Studying Surface Mechanical Properties. MRS Online Proceedings Library Archive, 153, 321-330. https://doi.org/10.1557/PROC-153-321

[16] Rokhlin, L.L. (2003) Magnesium Alloys Containing Rare Earth Metals: Structure and Properties. CRC Press, London. 